\title{
Correlating Student Beliefs With Student Learning Using The Colorado Learning Attitudes about Science Survey
}

\author{
K. K. Perkins, W. K. Adams, S. J. Pollock, N. D. Finkelstein and C. E. Wieman \\ Department of Physics, University of Colorado, Boulder, CO 80309
}

\begin{abstract}
A number of instruments have been designed to probe the variety of attitudes, beliefs, expectations, and epistemological frames taught in our introductory physics courses. Using a newly developed instrument - the Colorado Learning Attitudes about Science Survey (CLASS)[1] - we examine the relationship between students' beliefs about physics and other educational outcomes, such as conceptual learning and student retention. We report results from surveys of over 750 students in a variety of courses, including several courses modified to promote favorable beliefs about physics. We find positive correlations between particular student beliefs and conceptual learning gains, and between student retention and favorable beliefs in select categories. We also note the influence of teaching practices on student beliefs.
\end{abstract}

\section{INTRODUCTION}

In addition to the traditional content within any course, there are extensive sets of attitudes and beliefs about science that are taught to our students. How we conduct our class sends messages about how, why, and by whom science is learned. Such messages are being studied with the goal of developing more expert-like views on the nature and practice of science in our students. [2][3][4]

Over the last decade, physics education researchers have used several survey instruments to measure these attitudes and beliefs and to distinguish the beliefs of experts from the beliefs of novices. [5][6][7][8][9] Experts think about physics like a physicist. For instance, they see physics as being based on a coherent framework of concepts which describe nature and are established by experiment. Novices see physics as being based on isolated pieces of information that are handed down by authority (e.g. teacher) and have no connection to the real world, but must be memorized.

Data have shown that, traditionally, student beliefs become more novice-like over the course of a semester.[5] Even in courses using reformed classroom practices that are successful at improving student conceptual learning of physics, student beliefs tend not to improve.[4] Some success has been achieved, how- ever, in courses specifically designed to attend to student attitudes and beliefs.[2]

With these new measures of student beliefs about physics and about learning physics, the question emerges as to how these factors impact and are impacted by students' pursuit of physics study and their mastery of the content.[10] In this paper, we begin to examine the relationships among these different aspects of student learning. We look at: 1) the influence of teaching practices on student beliefs; 2) the relationship between students' beliefs about physics and their decisions about which physics course to take and whether to continue on in physics; and 3) the relationship between student beliefs about physics and their conceptual learning in the physics course.

\section{DATA}

The Colorado Learning Attitudes about Science Survey (CLASS)[1] was used to measure student beliefs at the start (pre) and end (post) of several introductory physics courses. The newly-developed CLASS survey builds on the existing attitude surveys (MPEX[5], VASS[6], EBABS[7]). The details of the design and validation of the CLASS are reported by Adams et al.[1] The survey consists of 38 statements to which students respond using a 5-point Likert scale. The 'Overall' favorable score is measured as the average percentage of statements to which the students 
answer in the favorable sense, e.g. as an expertphysicist would. The 'Overall' unfavorable score is similarly determined. The survey is used to measure specific belief categories by looking at subsets of statements. Here, we include measurements of the following facets: 'Conceptual Understanding' (physics is based on a conceptual framework), 'Math Physics Connection' (equations represent concepts), 'Sense Making / Effort' (I put in the effort to make sense of physics ideas), 'Real World Connection' (physics describes the world), and 'Personal Interest' (I think about physics in my life).

We look at the influence of teaching and at student's course selection and retention using data from six courses. These courses range in size (less than 40 to over 600 students), student population (non-science majors; pre-meds; physics, chemistry, and engineering majors), and school setting (from a large state research university (LSRU) to a mid-size multipurpose state university (MMSU)). Table 1 lists the courses as well as the other data available for each course.

We look at the correlation with conceptual learning using data from the LSRU's large calculus-based course in Spring 2004. The large number of the students allows us to examine sub-groups of students and retain good statistics. The structure of this course included multiple reforms designed to improve student learning and student beliefs, including interactive engagement in lecture, tutorial-style recitations, and an emphasis on conceptual understanding. In addition, the development and application of expert-like beliefs and approaches to problem solving were emphasized across the course components. For a detailed description of the reforms and an analysis of the contribution of various reforms to learning see Pollock.[11]

\section{RESULTS AND DISCUSSION}

Influence of teaching practices. In Table 1, we show the average pre- and post- 'Overall' percent favorable score for the six introductory physics courses. In bold, we see a decline of $9.8 \%$ for the Alg-I and
$8.2 \%$ for the Calc-I courses taught at MMSU. While the Alg-I course was traditionally taught, the Calc-I course was taught using interactive engagement methods; however, neither course specifically attended to improving student attitudes and beliefs about physics. These declines are consistent with those observed in similar courses.[5] In contrast, we do not see these declines in the LSRU courses. All of these LSRU courses incorporated teaching practices specifically aimed at improving student beliefs. Despite being constrained to a large lecture format, these courses resulted in increases of $1-2 \%$ in the 'Overall' score.

Course selection and retention. The courses listed in Table 1 represent a range of commitments to the study of physics. We see that the students' incoming favorable beliefs on the 'Personal Interest' category increases with the level of the physics course in which students enrolled. The non-science majors average only a $54 \%$ favorable belief while the average for the course for physics majors is $74 \%$. Thus, students who make larger commitments to studying physics tend to be those who identify physics as being relevant to their own lives - as measured by 'Personal Interest'.

In addition, we see that the non-science majors who chose to continue and take the second term had significantly more favorable 'Overall' and 'Personal Interest' beliefs than those who did not - their scores being $14 \%$ and $15 \%$ more expert-like, respectively. For the MMSU Alg-I course, a significant number of students (41) dropped the course. The students who completed the course had a substantially higher favorable 'Personal Interest' score initially (64\%) than those who dropped (49\%). These two pieces of data suggest a link between retention of students (both within and across courses) and students' favorable beliefs.

Student Beliefs and Conceptual Learning. The LSRU's large calculus-based courses were highly successful at achieving their goal to improve student learning.[11] On two standard exams for measuring conceptual learning, the students achieved median normalized gains of 0.67 on the FCI[12] (Fall 2003) and 0.76 on the FMCE[13] (Spring 2004). While the

TABLE 1. Evident correlations between favorable 'Personal Interest' and physics course selection

\begin{tabular}{|c|c|c|c|c|c|c|c|c|}
\hline \multirow{2}{*}{$\begin{array}{c}\text { Course } \\
\text { Type }\end{array}$} & \multirow{2}{*}{$\begin{array}{c}\text { School } \\
\text { Type/Term }\end{array}$} & \multirow{2}{*}{$\begin{array}{l}\text { Dominant } \\
\text { student } \\
\text { population }\end{array}$} & \multirow{2}{*}{$\begin{array}{c}\text { \# of } \\
\text { students } \\
\text { w/ CLASS }\end{array}$} & \multirow{2}{*}{$\begin{array}{l}\text { Normalized } \\
\text { learning } \\
\text { gains }\end{array}$} & \multicolumn{3}{|c|}{ 'Overall' \%favorable ${ }^{\$}$} & \multirow{2}{*}{$\begin{array}{c}\text { 'Personal Interest' } \\
\text { \% favorable on Pre-test } \\
\text { (Std. Error of Mean) }\end{array}$} \\
\hline & & & & & Pre & Post & Shift (Std. Err) & \\
\hline Non-Sci-I & LSRU/Fa03 & non-sci & 76 & & $57 \%$ & $58 \%$ & $+1.0 \%(1.5 \%)$ & $54 \%(3 \%)$ \\
\hline Non-Sci-II & LSRU/Sp04 & non-sci & 36 & & $71 \%$ & $72 \%$ & $+1.4 \%(2.2 \%)$ & $69 \%(5 \%)$ \\
\hline Alg-I & MMSU/Fa03 & pre-meds & 35 & g_FCI $=0.13$ & $63 \%$ & $53 \%$ & $-9.8 \%(2.8 \%)$ & $64 \%(3 \%)$ \\
\hline Calc-I & LSRU/Fa03 & engineers & 168 & g FCI $=0.67$ & $65 \%$ & $67 \%$ & $+1.5 \%(1.2 \%)$ & $70 \%(2 \%)$ \\
\hline Calc-I & LSRU/Sp04 & engineers & 398 & g_FMCE $=0.76$ & $68 \%$ & $70 \%$ & $+1.5 \%(0.7 \%)$ & $72 \%(1 \%)$ \\
\hline Calc-I & $\mathrm{MMSU} / \mathrm{Fa} 03$ & physics maj & 38 & g $\quad \mathrm{FCI}=0.35$ & $65 \%$ & $57 \%$ & $-8.2 \%(2.7 \%)$ & $74 \%(4 \%)$ \\
\hline
\end{tabular}


TABLE 2. Correlations between beliefs and learning

\begin{tabular}{|c|c|c|}
\hline \multirow[t]{2}{*}{$\begin{array}{c}\text { Belief } \\
\text { category }\end{array}$} & \multicolumn{2}{|c|}{$\begin{array}{c}\text { Correlations of } \\
\text { normalized FMCE gain with* }\end{array}$} \\
\hline & $\begin{array}{c}\text { Pre-beliefs } \\
\text { (p-value) }\end{array}$ & $\begin{array}{c}\text { Post-beliefs } \\
\text { (p-value) }\end{array}$ \\
\hline Overall & $0.21(0.0008)$ & $0.26(0.00002)$ \\
\hline Conceptual Underst & $0.22(0.0005)$ & 0.00001 \\
\hline Math Physics Conne & $0.20(0.001)$ & $.001)$ \\
\hline Sense Making / Effort & $0.11(0.09)$ & 007) \\
\hline Personal Interest & $0.03(0.63)$ & $0.15(0.01)$ \\
\hline Real World Connection & $0.02(0.79)$ & $0.08(0.19)$ \\
\hline
\end{tabular}

median normalized gain was quite high, some students had significantly smaller learning gains and a large number of students had much higher learning gains. With pre/post CLASS and FMCE data on 307 students from Spring 2004, we are able to explore the relationship between students' beliefs and their learning gains.

In Table 2, we show the correlations between students' beliefs and their normalized learning gain. We limit these to the $90 \%$ of the students who had FMCE pre-test scores $<60$ (Thornton's level of conceptual mastery) because we are interested in students who have not already mastered the material $(\mathrm{N}=256)$. [13] The correlations in the various belief categories range from 0.02 to 0.22 for pre and 0.08 to 0.30 for post. We see the categories of 'Conceptual Understanding' and 'Math Physics Connection' have correlations with learning gains that are statistically different from zero; where as, 'Real World Connection' and 'Personal Interest' do not. It makes sense that expert beliefs in these former two categories are more important to the form of learning measured by the FMCE. We also see larger correlations with post-beliefs than pre-beliefs in almost all categories. While these correlations are small, it is notable that they are larger than the correlations of learning gain with homework, attendance, and a math pre-test, which are all 0.22 or lower.[11]

In Figure 1, we show students average pre- and post- beliefs as a function of normalized learning gain for 'Overall' and 'Conceptual Understanding'. Two trends emerge: (1) students with higher conceptual gains tend to have more favorable beliefs in these categories and (2) students in the lowest gain category tend to regress in beliefs, while higher performing students tend to post gains in beliefs.

It is important to note that the correlations between beliefs and learning gain listed in Table 2 apply to this course with its teaching practices, student population, and curriculum and with its choice of instrument for measuring conceptual learning. Changes to any of these elements can effect the correlations with beliefs. Analysis of the observed affect can then help interpret the meaning of the change and provide some more in-

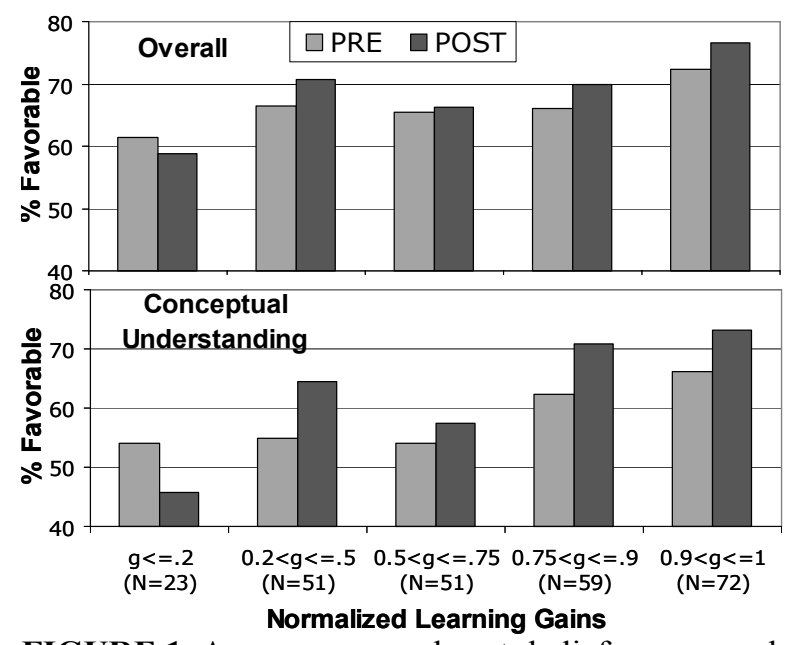

FIGURE 1. Average pre- and post- beliefs vs. normalized conceptual learning gain.

sight into the relationship of student beliefs and learning. For example, the Fall 2003 LSRU course had the same instructor (Pollock) using the same teaching practices and materials, but using a different measure of conceptual learning gain (the FCI). While the data do show the same general trends as observed in Figure 1, they show somewhat stronger correlations between normalized learning gain and students' beliefs. In addition, some categories which show relatively weak correlations here show stronger correlations with the FCI learning gain, and vise versa. These differences likely reflect the differences in the learning measured by the two instruments.[13]

The correlations reported here are between individual belief categories and normalized learning gain. If multiple categories contribute to improved learning, it is likely that a weighted combination of categories would result in higher correlation coefficients and is a topic of future analysis. Higher correlations may also result from the ongoing refinement of the CLASS statements and categories to better probe beliefs.[1]

As a start to understanding possible cause and effect, we have looked further at the relationship between pre-belief and normalized learning gain and the meaning of the observed correlation of 0.21 . In Figure 2 , we have binned the students by their incoming 'Overall' belief and plotted the percent of students within each belief bin who achieve learning gains of greater than $0.8,0.8$ to 0.3 , and less than 0.3 . We see that over $50 \%$ of the students with favorable incoming beliefs of $80-100 \%$ achieve normalized learning gains in excess of 0.8 and that this percentage decreases for each successive bin while the percentage of students with learning gains less than 0.3 increases. A chisquared test shows that the observed combination of distributions of students within each bin are statistic- 


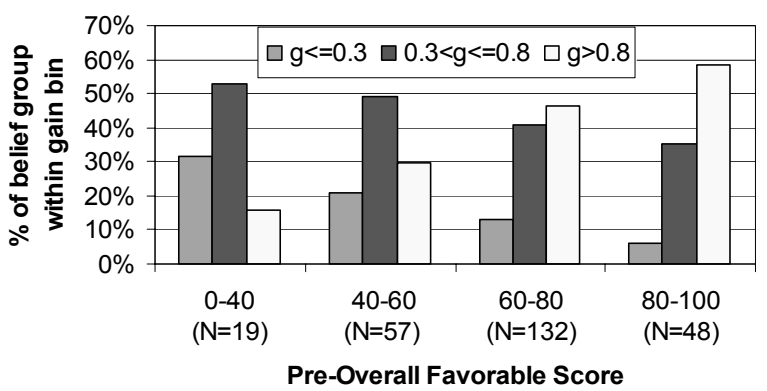

FIGURE 2. Conceptual learning gain vs. Pre'Overall' belief.

cally different $(\mathrm{p}=0.006)$ from the class-average distribution $-14 \% \mathrm{~g}<0.3,43 \% \quad 0.3<\mathrm{g}<=0.8,43 \% \mathrm{~g}>0.8$. These data are consistent with the idea that students' beliefs about science when they enter a course influence their conceptual learning. Of course, we cannot rule out the alternative conclusion that other factors are simultaneously influencing both students' incoming beliefs and their conceptual learning.

It is also interesting to consider how learning is impacting or impacted by changes in students' beliefs over the course of the term. One approach is to select a subgroup of students with nearly identical incoming beliefs and look at the connection between their shift in beliefs and their learning gain. We preformed an analysis of this type for the data presented here. The results are suggestive of a positive relationship between occurrence of favorable shifts in beliefs over the course of the term and higher learning gains, but additional data is necessary to investigate this further.

\section{CONCLUSION}

Our analysis of students' attitudes and beliefs measured using the CLASS suggests that beliefs play a role both in the physics courses students choose to take and in their retention within those courses and in the discipline. In addition, we observe positive correlations between student beliefs and normalized conceptual learning gains. We see that students who come into a course with more favorable beliefs are more likely to achieve high learning gains. These data are consistent with the idea that beliefs are a factor in student learning; however, we must consider the possibility that other factors are simultaneously influencing students' beliefs, their learning, and their choices in pursuing physics. In our work, we found that it is possible to create environments, even in large lecture courses, that support improved student beliefs about physics and that this specific attention can avoid the common decline in beliefs commonly observed in introductory physics courses.

\section{ACKNOWLEDGMENTS}

The authors thank NSF for providing the support for this work. We are also very grateful to all of the instructors who generously agreed to administer the CLASS in their courses. We also give thanks to all the members of the Physics Education Research at Colorado group for many valuable discussions.

\section{REFERENCES}

1 W. Adams et al., "Design and Validation of the Colorado Learning About Science Survey" in review for Proceedings of the PERC 2004, Sacramento, CA. http://cosmos.colorado.edu/phet/survey/CLASS/

2 D. Hammer, Am. J. Phys. 68, S52-S59 (2000).

3 A. Elby, Am. J. Phys. 69, S54-S64 (2001).

4 Redish, Teaching Physics with Physics Suite, Wiley 2003

5 E.F. Redish, J.M. Saul, and R.N. Steinberg, Am. J. Phys. 66, 212-224 (1998).

6 I.A. Halloun, "Views About Science and Physics Achievement: The VASS Story." In The Changing Role of Physics Departments in Modern Universities: Proceedings of the ICUPE.

7 A. Elby, Epistemological Beliefs Assessment for Physical Science http://www2.physics.umd.edu/ elby/EBAPS/ home.htm

8 D. Hammer, "Misconceptions or p-prims: How may alternative perspectives of cognitive structure influence instructional perceptions and intentions?" Journal of the Learning Sciences, 5, 97-127, (1996). D. Hammer, "More than misconceptions: multiple perspectives on student knowledge and reasoning, and an appropriate role for education research," Am. J. Phys., 64, 13161325, (1996). D. Hammer, "Discovery learning and discovery teaching," Cognition and Instruction, 15, 485529, (1997).

9 Chi, M.T.H, Feltovich, P.J., and Glaser, R. "Categorization and representation of physics problems by experts and novices," Cognitive Science, 5, 121-152, (1981).

10 A. Schoenfeld, "What's all the fuss about metacognition," in A. Schoenfeld, Cognitive science and mathematical education. Philadelphia: Lawrence Erlbaum. 1987.

11 S. Pollock, "No Single Cause: Learning Gains, Student Attitudes, and the Impacts of Multiple Effective Reforms" in review for Proceedings of the PERC 2004, Sacramento, CA.

12 R. Hake, Am. J. Phys. 66, 64-74, (1998)

13 R. Thornton and D. Sokoloff, Am. J. Phys. 66, 338-352, (1998); also R. Thornton, D. Kuhl, K. Cummings, and J. Marx, "Comparing the FMCE and the FCI", unpublished. 